\title{
Ethics, Foreseeability, and Tragedy in Australian Immigration Detention
}

\author{
Ryan Essex
}

Received: 22 January 2015 / Accepted: 1 November 2015 /Published online: 1 December 2015

(C) Journal of Bioethical Inquiry Pty Ltd. 2015

The death of Hamid Kehazaei, an asylum seeker detained on Manus Island, has raised a number of questions surrounding the medical treatment he received and whether a move to mainland Australia, if expedited, could have saved him. He died of severe septicaemia from an infected cut, and the circumstances surrounding his death were largely unknown until medical documents were recently obtained by the Australian Broadcasting Corporation (ABC) (Willacy, Solomons, and McDonald 2014). In these documents it was revealed that all treatment options on Manus Island had been exhausted, with recommendations for a transfer for further treatment made by International Health and Medical Services (IHMS), the medical provider on Manus. The initial request for a transfer to Port Moresby was made on August 25, 2014, which was subsequently delayed for more than twenty-four hours. He was then transferred to Brisbane on the afternoon of August 27 and pronounced dead on September 5. The ethical issues raised by this case are not isolated and are only part of long-term systemic failings that have compromised the health and well-being of those in immigration detention.

According to the The Border Crossing Observatory (2015). there have been at least thirty-four deaths in immigration detention or community detention since 2000. At least eleven of these were suicides or suspected

\section{R. Essex $(\bowtie)$}

Centre for Values, Ethics and the Law in Medicine, The University of Sydney, Sydney, NSW, Australia

e-mail: ryan.essex@sydney.edu.au suicides. Hamid Kehazaei is one of three individuals who have died in offshore detention. These deaths have been set to a backdrop of epidemic levels of self-harm and poor physical and mental health. The immigration department itself acknowledged the link between prolonged immigration detention and deteriorating mental health at the Australian Human Rights Commission (AHRC) hearings into children in detention (Marr and Laughland 2014).

The devastating impact immigration detention has upon health and multiple deaths in custody have prompted numerous investigations. The Commonwealth Ombudsman's (2013) report into suicide and self-harm in immigration detention was critical of how policies and practices were implemented. Specifically, and with particular resonance for the above case, the Ombudsman commented on the placement of asylum seekers within the detention network in relation to their health and wellbeing. At the time, these decisions were guided by the Detention Facility Client Placement Model. This model guided placement decisions for onshore detention; it is not clear how placement is determined in offshore locations.

The department's duty of care to detainees extends to the decisions it makes about where a detainee is placed in the detention network. For example, if a person detained in a detention facility in a remote location requires medical services that are not practically available to them in that facility, then the department's duty of care may require it to relocate the detainee to another facility where those services are available (Commonwealth Ombudsman 2013, 87). 
During the AHRC hearings into children in detention, Dr. Peter Young, the former medical director of IHMS, gave a first-hand account of the harms of immigration detention, along with the immigration department's disregard for medical advice, warning about delays in transferring asylum seekers to the mainland for treatment.

It is seen as undesirable because it undermines the idea that people are never going to Australia and also because of the concern that if people arrive onshore then they may have access to legal counsel and other assistance (Marr and Laughland 2014, ๆ7).

These concerns were further supported when the $\mathrm{ABC}$ revealed documents that provided a confidential assessment of IHMS' performance by the department of immigration in providing medical care and meeting contractual arrangements (Om 2014). The findings were based on a meeting of eight senior bureaucrats and accused clinicians of advocating for asylum seekers, including recommending excessive medical procedures. Frustrations were also noted about clinicians recommending asylum seekers be transferred to the mainland for treatment. To address these concerns, the report suggested that IHMS hire clinicians who were able to better follow the contractual requirements and who were not against offshore processing. According to this report, IHMS would be risking its contract with the department if the concerns were not addressed.

The long-standing reluctance of the immigration department to follow medical advice (e.g., Australian Heads of Schools of Social Work [ACHSSW] 2006) reflects the level of control it maintains over detention centres and how drastically the department's interests diverge from clinicians working within the system. For those who work in immigration detention, the lack of clinical independence is an overarching ethical issue, with clinicians compromised by the additional obligations placed on them by the department and IHMS (e.g., Coffey 2006; Essex 2014). These systemic failures and the pressure placed on clinicians to conform to a damaging system often go unreported; however, there are a number clinicians beginning to speak about their experiences in detention, showing the extent to which medical recommendations are subordinated by other policies.

A number of such ethical issues were highlighted by a letter written by fifteen doctors to IHMS and subsequently provided to The Guardian in late 2013. The letter revealed the inadequate conditions under which IHMS provided medical treatment on Christmas Island and that underpinning almost all of these complaints was the fact that patient care was compromised by IHMS' relationship with the department of immigration (Laughland and Marr 2013). The letter states:

A conflict of interest exists, as a result of IHMS' relationship with the Department of Immigration and Border Protection that can influence decisions regarding patient care. Decisions made by IHMS do not appear to have always been made in the best interest of patients. The shifting of responsibility between the DIBP and IHMS is likely to result in neither party acting appropriately in regards to patients (Names redacted in The Guardian 2014, 5).

Furthermore these decisions place medical and nurse practitioners at great medico-legal risk, a fact that goes uncontested by management at staff meetings and yet has not been addressed. Management states that the Department of Immigration are accepting all responsibility. However, no third party has the power to absolve health practitioners of their duty of care to patients and we must all adhere to AHPRAs code of conduct (Names redacted in The Guardian 2014, 29).

The doctors specifically raised concerns about the placement of patients, providing a number of salient examples.

During these delays, medical staff attempt to manage these often complex and painful conditions with ad hoc and temporising measures. The waiting time is indeterminate and no advice can be given as to when a person is to leave for definitive care. ... The conditions can be so severe that they risk lifethreatening deterioration. Cases include an individual with an imminent risk of sepsis from surgical pathology, complications of a pacemaker insertion in a child and fevers in a patient with undifferentiated immune-compromise (Names redacted in The Guardian 2014, 32).

Despite multiple warnings, numerous investigations, and the dire health of those detained, little has been done to address the numerous systemic failures and barriers to providing ethical healthcare in immigration detention. 
One of the greatest tragedies of the Hamid Kehazaei case is the fact that the issues surrounding it were long known, as was the fact that treatment recommendations were regularly subordinated to the department's interests. Such issues were raised by multiple individuals and enquiries in the months and years leading up to Hamid Kehazaei's death. The idea of a coordinated response, including discussing the implications of a boycott by healthcare professionals, was raised by a number of doctors who were involved in writing the above Christmas Island letter (Sanggaran, Ferguson, and Haire 2014). What is certain is that change is now long overdue and that bold action is needed, because as long as healthcare in immigration detention remains compromised and undermined, the next tragedy is not only foreseeable but inevitable.

\section{Update}

Since this editorial was written in mid-2014, there have been four further deaths related to Australia's asylum seeker polices, two in onshore immigration detention centres (The Border Crossing Observatory 2015). There also have been a number of investigations that have detailed widespread sexual and physical abuse, selfharm, suicide, and mental health issues in offshore immigration detention centres (Australian Human Rights Commission 2014; Moss 2015; Select Committee on the Recent Allegations Relating to Conditions and Circumstances at the Regional Processing Centre in Nauru 2015). This has all occurred while the government has passed legislation that could send clinicians to gaol for up to two years for raising concerns about abuse and neglect (Hoang 2015).

A Coronial Inquest in Queensland into the death of Hamid Kehazaei also has recently begun. It is hoped that this sheds further light on the above events and is a step toward change and justice.

\section{References}

Australian Heads of Schools of Social Work (ACHSSW). 2006. We've boundless plains to share: The first report of the People's Inquiry into Detention. Melbourne: Australian Council of Heads of Schools of Social Work.
Australian Human Rights Commission. 2014. The forgotten children: National inquiry into children in immigration detention. Sydney: Australian Human Rights Commission.

Coffey, G. 2006. "Locked up without guilt or sin": The ethics of mental health service delivery in immigration detention. Psychiatry, Psychology and Law 13(1): 67-90.

Commonwealth Ombudsman. 2013. Suicide and self-harm in the immigration detention network. Canberra: Commonwealth Ombudsman.

Essex, R. 2014. Human rights, dual loyalties, and clinical independence. Journal of Bioethical Inquiry 11(1): 75-83.

Hoang, K. 2015. Border force act entrenches secrecy around Australia's asylum seeker regime. The Conversation, July 2. https://theconversation.com/border-force-act-entrenchessecrecy-around-australias-asylum-seeker-regime-44136. Accessed July 10, 2015.

Laughland, O., and D. Marr. 2013. Rush to send asylum seekers offshore may risk lives, doctors warn. The Guardian Australia, December 20. http://www.theguardian.com/ world/2013/dec/20/rush-to-send-asylum-seekers-offshoremay-risk-lives-doctors-warn. Accessed August 5, 2014.

Marr, D., and O. Laughland. 2014. Australia's detention regime sets out to make asylum seekers suffer, says chief immigration psychiatrist. The Guardian Australia, August 5. http:// www.theguardian.com/world/2014/aug/05/-sp-australiasdetention-regime-sets-out-to-make-asylum-seekers-suffersays-chief-immigration-psychiatrist. Accessed August 5, 2014.

Moss, P. 2015. Review into recent allegations relating to conditions and circumstances at the Regional Processing Centre in Nauru. Canberra: Department of Immigration and Border Protection.

Om, J. 2014. Leaked immigration document reveals disagreements with detention centre doctors. $A B C N e w s$, December 12. http://www.abc.net.au/news/2014-12-12/medical-stafftreating-asylum-seeker-advocating-for-detainees/5962106. Accessed December 12, 2014.

Sanggaran, J.-P., G.M. Ferguson, and B.G. Haire. 2014. Ethical challenges for doctors working in immigration detention. The Medical Journal of Australia 201(7): 1-3.

Select Committee on the Recent Allegations Relating to Conditions and Circumstances at the Regional Processing Centre in Nauru. 2015. Taking responsibility: Conditions and circumstances at Australia's Regional Processing Centre in Nauru. Canberra: Parliament of Australia.

The Border Crossing Observatory. 2015. Australian border deaths database. http://artsonline.monash.edu.au/ thebordercrossingobservatory/publications/australianborder-deaths-database/. Accessed November 2, 2015.

The Guardian (names of authors redacted). 2014. Christmas Island doctors' letter of concern. The Guardian, January 13. http:// www.theguardian.com/world/interactive/2014/jan/13/ christmas-island-doctors-letter-of-concern-in-full.

Willacy, M., M. Solomons, and M. McDonald. 2014. Hamid Kehazaei case: Seriously ill asylum seeker forced to wait more than 24 hours for medical transfer. $A B C$ News, December 8. http://www.abc.net.au/news/2014-12-08/illfated-asylum-seeker-forced-to-wait-for-medical-transfer/ 5952756. Accessed December 11, 2014. 